\title{
Minimally invasive asterional approach for microvascular decompression in trigeminal neuralgia
}

\author{
Ramiro López-Elizalde ${ }^{1,2}$, Esteban Reyes-Velasco ${ }^{1}$, Álvaro Campero³, Pablo Ajler ${ }^{4}$, \\ Karla Cecilia Cornelio-Freer ${ }^{1}$ and Marisol Godínez-Rubi ${ }^{1,5 *}$ \\ ${ }^{1}$ Health Regulatory Directorate, Instituto de Seguridad y Servicios Sociales de los Trabajadores del Estado, City of Mexico; ${ }^{2}$ Neurosurgery \\ Department, OPD Hospital Civil Juan I. Menchaca, Guadalajara, Jalisco, Mexico; ${ }^{3}$ Neurosurgery Department, Hospital Padilla, Tucumán, Argentina; \\ ${ }^{4}$ Department of Neurological Surgery, Hospital Italiano, Buenos Aires, Argentina; ${ }^{5}$ Department of Microbiology and Pathology, University Center of \\ Health Sciences, Universidad de Guadalajara, Guadalajara, Jalisco, Mexico
}

\begin{abstract}
Objective: Trigeminal neuralgia (TN) is a neuropathic disorder that can be treated surgically. This study aimed to present the surgical findings and the clinical outcomes of 26 patients with TN treated by minimally invasive asterional surgery. Methods: Longitudinal descriptive study. Twenty-six patients with TN underwent minimally invasive asterional surgery. The medical history, surgical findings, therapeutic response, and complications were registered. They were followed for 36 months. Results: Nineteen cases were associated with vascular compression; five were associated with arachnoiditis. The two remaining cases were associated with multiple sclerosis and post-herpetic neuralgia. The pain was substantially reduced in all patients in the immediate postoperative period. At 36 months, in 25 patients, total or acceptable pain control was achieved. In the long term, 22 patients evolved with no permanent complications. Conclusion: The microvascular decompression surgery by an asterional approach is an alternative with similar results to the classic retrosigmoid approach to treat TN, but that adds the benefits of the principles of minimally invasive surgery. Constant efforts need to be made to optimize minimally invasive surgical techniques for $T N$.
\end{abstract}

KEY WORDS: Trigeminal neuralgia. Microvascular decompression surgery. Minimally invasive neurosurgery. Asterional approach.

\section{Introduction}

Trigeminal neuralgia (TN) is a paroxysmal neuropathic disorder that affects one (or all) sensory branches of the trigeminal nerve ${ }^{1,2}$. Several studies reveal a global incidence of approximately 12.6-28.9 cases per 100,000 individuals per year ${ }^{3}$. The pathophysiological mechanism of this entity is uncertain in most cases. Compression by a neighboring blood vessel is accepted as the most common cause, most frequently the superior cerebellar artery $(\mathrm{SCA})^{4,5}$.

Initial treatment is always medical, but the patient may eventually require percutaneous treatment, rhizotomy or microvascular decompression (MVD) surgery ${ }^{6}$. Trigeminal nerve MVD is an effective and accepted treatment for TN. It was first performed by Frazier in 1915 through a transtemporal approach. It was later improved by Dandy in 1934, who proposed a subcerebellar approach. Gardner Miklos renewed interest in MVD surgery in $1962^{1,7}$; however, it was Jannetta who popularized the currently used technique ${ }^{7,8}$.

To improve postoperative results, some authors have chosen to refine the MVD surgical technique ${ }^{9-15}$. In this work, we present our experience in the surgical treatment of TN through a minimally-invasive asterional approach for trigeminal vascular decompression.
Gac Med Mex. 2019;155 (Suppl 1):S56-S63

Contents available at PubMed www.gacetamedicademexico.com 

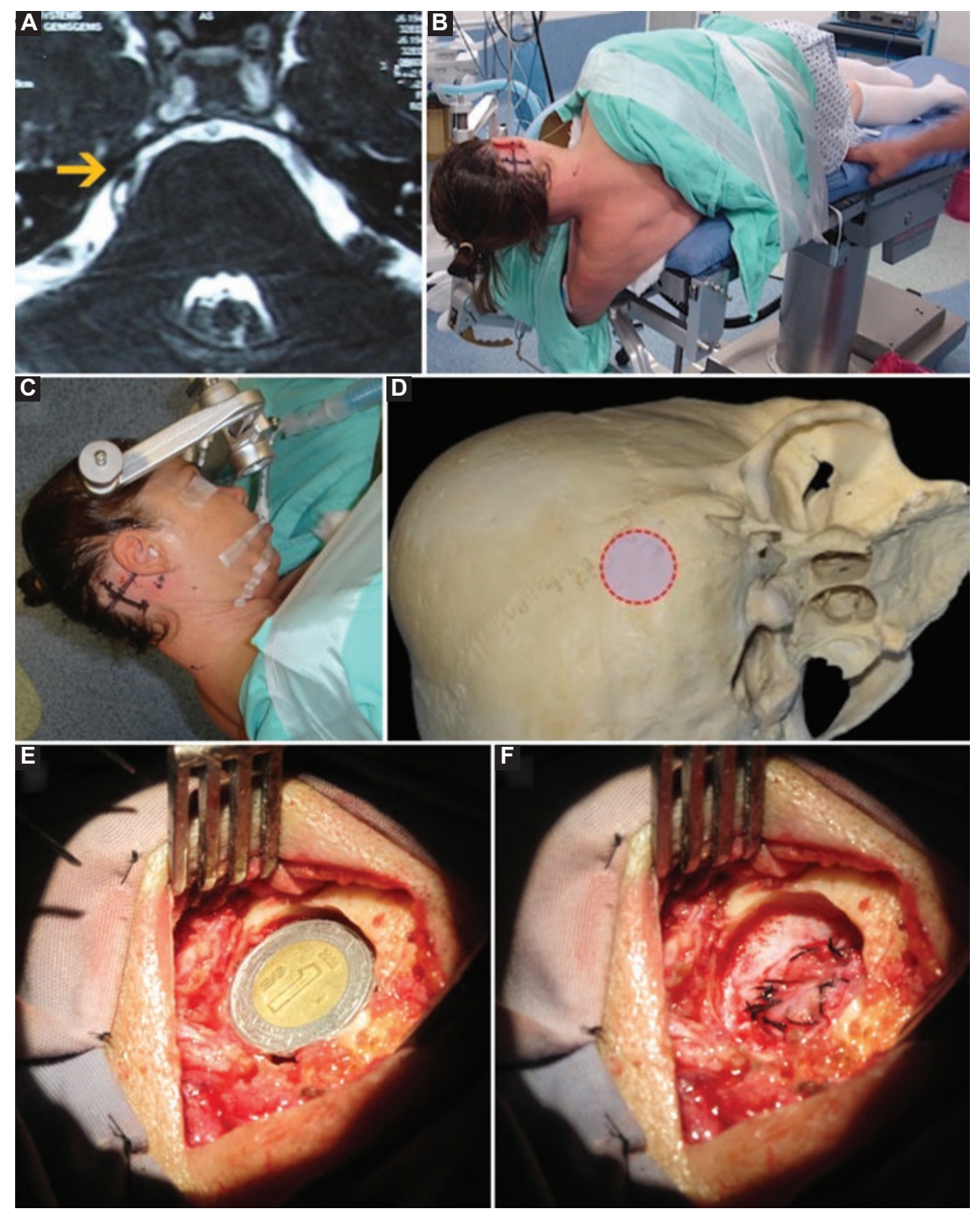

Figure 1. A: Pre-operative T2-weighted MRI FIESTA sequence showing a vascular loop of the AICA exerting compression on the trigeminal nerve (yellow arrow); B: the patient is placed in the Park Bench position, in lateral decubitus with knees and hips in flexion and contralateral arm perpendicular to the floor; C: head fixation with Mayfield head holder with $45^{\circ} \mathrm{m}$ rotation contralateral to the affected side; the skin incision is curvilinear and is made between the zygomatic line and the mastoid line; $\mathbf{D}$ : craniotomy model (dotted line), performed posterior and inferior to the Asterion; in this position, the upper border of the craniotomy is located over the transverse and sigmoid sinuses; $\mathrm{E}$ : The size of the bone window (18-25 mm) is illustrated, with a 21-mm coin used for comparison; F: craniotomy size and dural closure after concluding the procedure.

\section{Material and Methods}

\section{Patients}

A longitudinal, descriptive study was conducted that included 26 patients with TN who had had recurrent and persistent disability symptoms despite standard medical treatment for at least two years, or subjects who showed intolerance to the medication. All cases underwent minimally invasive surgery by means of asterional microcraniectomy. The collected information included age, gender, evolution time, medical history, pain characteristics, surgical findings, complications and postoperative evolution.

\section{Pre-surgical assessment}

Prior to surgery, all patients underwent a complete neurological examination and cranial magnetic resonance imaging (MRI) using the FIESTA sequence. Structural damage was ruled out in the MRI, and relevant anatomical structures were located such as the dorsal root of the trigeminal nerve, the SCA, the petrosal vein, the anterior inferior cerebellar artery 

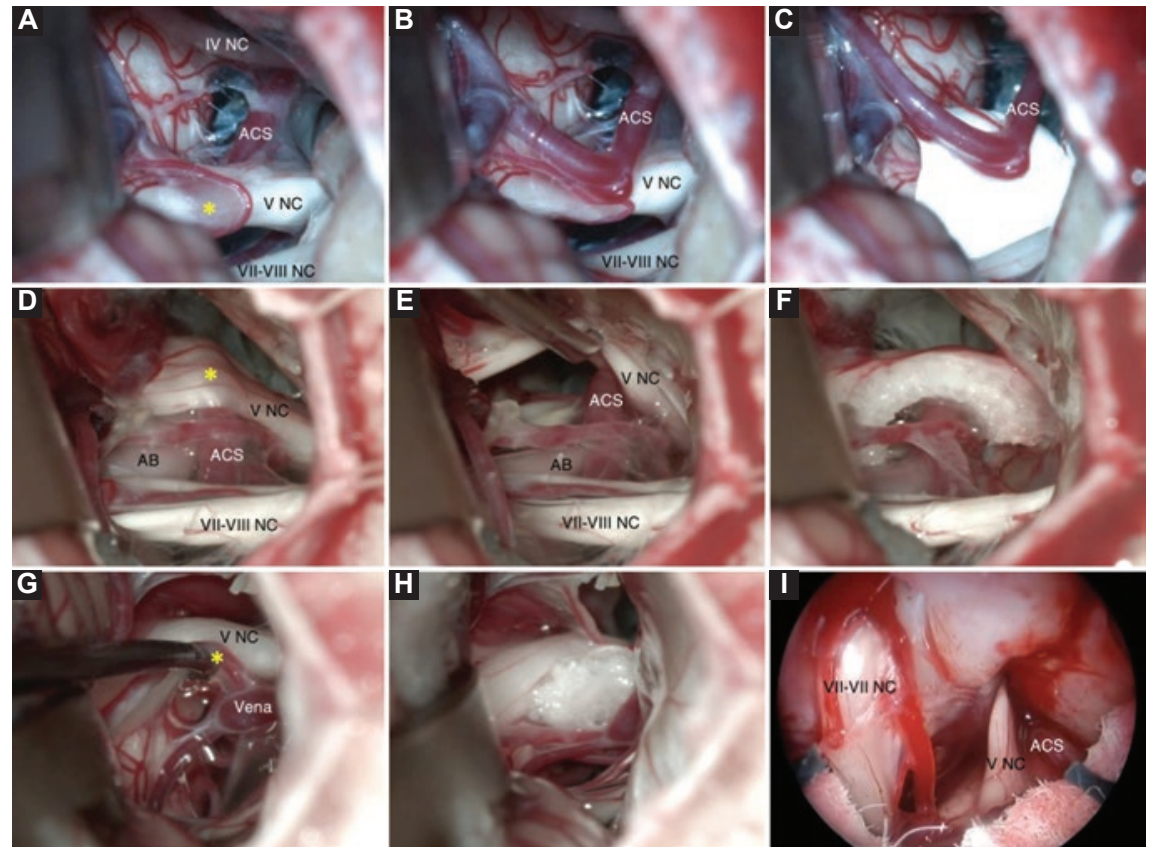

Figure 2. Intradural exposure of cerebrovascular structures within the cerebellopontine cistern through a minimally-invasive asterional approach in three different patients. Patient 1, figures A, B and C; A: view of the surgical field after dural opening and cistern drainage. The trigeminal nerve is located in front of an SCA loop it establishes evident contact with (*) and which is adhered by arachnoids; $\mathrm{B}$ : Trigeminal nerve and SCA once adherences have been released by arachnoid tissue removal; C: nerve and artery have been separated by placing insulating material in between. Patient 2, figures D to F; D: the trigeminal nerve passes above the SCA with contact in between; $\mathrm{E}$ : once the nerve is elevated, the close relationship between both structures can be observed; $\mathbf{F}$ : total interposition of the insulating material to prevent greater compression of the trigeminal nerve. Patient 3, figures $\mathrm{G}$ and $\mathrm{H}$. In this case, two vessels (artery and vein) are adjacent to the trigeminal nerve G; $\mathrm{H}$ : vascular and nervous structures separation after arachnoid dissection; I: endoscopic view once the nerve is released. It shows the close relationship between the nerve bundle formed by cranial nerves VII-VIII and the complex formed by the trigeminal nerve and the SCA. The asterisks mark the point where the vascular structure makes contact with the trigeminal nerve (anterior or posterior) at each case. AB: basilar artery; ACS: superior cerebellar artery; IV NC: fourth cranial nerve (trochlear nerve); V NC: fifth cranial nerve (trigeminal nerve); VII NC: seventh cranial nerve (facial nerve); VIII NC: eighth cranial nerve (vestibulocochlear nerve).

(AICA), the cerebellopontine angle (CPA) cisterns, the internal auditory canal and cranial nerves VII and VIII, as well as the tympanic artery (Fig. 1A). The following reference points were also identified: external acoustic meatus, the mastoid portion of the temporal bone and its pneumatization, the supramastoid crest, upper and lower nuchal lines and the arachnoid space in the cerebellar fossa.

\section{Surgical technique description}

A checklist is made for surgical material, as well as for the anesthetic technique, the side to be operated (previously marked) and for all the supplies for the surgery. The patient is placed in a prone position (three quarters) with the head turned to the opposite side and the neck slightly bent, the ipsilateral shoulder is fixed down and forward, the knees and hips are flexed and the arm is placed $90^{\circ}$ perpendicular to the floor (Park Bench position) (Fig. 1B). The patient's head is fixed with a Mayfield head holder and turned $45^{\circ}$ contralaterally to the side affected by neuralgia with a slight flexion (Fig. 1C). The table is tilted to raise the head holder. The area of interest is prepared by means of shaving and aseptic technique. A vertical or curvilinear paramedian incision is made between the zygomatic and mastoid lines, crossing the asterion (Fig. 1C). The skin is deeply incised down to the muscular fascia, the use of monopolar electrocautery should be avoided. The selection of the precise point for skin incision and craniotomy is supported by information provided by the neuronavigation systems, which allows obtaining an exact view of the anatomical relationship the asterion has with the transverse sinus and sigmoid sinus. Once the asterional point has been identified ${ }^{16,17}$ (Fig. 1D), a microcraniotomy of approximately $21 \mathrm{~mm}$ (range 18-25 mm) is performed (Fig. $1 \mathrm{E}$ and F). Accessing the mastoid cells should be avoided; if this occurs, they should be carefully sealed with bone wax.

The superolateral margin of the craniotomy should coincide with the attachment point of the inferior border of the transverse and sigmoid sinuses. The dura 
Table 1. Scale for therapeutic response assessment

\begin{tabular}{|c|c|c|}
\hline Category & Status & Description \\
\hline A & No pain & No episodes of neuralgia or pain crisis during the period between surgery and each assessment. \\
\hline B & Good pain control & $\begin{array}{l}\text { One or more episodes of pain during the period between surgery and each assessment, on the } \\
\text { same dermatome. Pain is not disabling or affects daily activities. Pain responds satisfactorily to } \\
\text { non-steroidal analgesics. }\end{array}$ \\
\hline C & Slight pain control & $\begin{array}{l}\text { Two or more episodes of pain during the period between surgery and each assessment, on the } \\
\text { same dermatome. Pain is not disabling or affects daily activities. Pain is relieved with the same drug } \\
\text { treatment used prior to surgery. }\end{array}$ \\
\hline D & Failure in pain control & $\begin{array}{l}\text { Two or more episodes of disabling pain or that interrupt daily activities during the period between } \\
\text { surgery and each assessment. The pain requires the same treatment used prior to surgery. }\end{array}$ \\
\hline
\end{tabular}

mater is curvilinearly opened, following the craniotomy margins, $2 \mathrm{~mm}$ below the transverse sinus and $2 \mathrm{~mm}$ below the sigmoid sinus.

After dural opening, cerebrospinal fluid (CSF) drainage of the cisterna magna and CPA cisterns is performed under gentle aspiration. Lumbar drainage is not systematically performed. If the cerebellum obstructs the surgical field, a separator is gently placed to contain it.

Once the CPA is exposed, the surgical microscope vector is directed towards it, with emphasis on the upper sector. It is necessary to visualize the trigeminal nerve along its entire cisternal course (Fig. 2) in order to dissect the arachnoid that covers it in its full extension (Fig. 2 A-G). Any manipulation of cranial nerves VII and VIII neurovascular complex should be prevented in order to avoid complications.

Once the trigeminal nerve is exposed, any vascular structure (arterial or venous) compressing it must be identified and moved away from the nerve (Fig. 2 B, E and G). To avoid contact between the nerve and the blood vessel, an insulating material is inserted in between (Fig. $2 \mathrm{C}, \mathrm{F}$ and $\mathrm{H}$ ) and, if necessary, it is fixed with fibrin glue. If no vascular contact can be visualized, the procedure can be assisted by a neuroendoscope (Fig. 2l).

Once hemostasis is verified, the wound is irrigated, the dura mater is closed by approaching the dural borders, and the pericranium and muscle are sutured with silk and continuous sutures (Fig. 1F). When available, the bone flap is put in place to close the craniotomy; otherwise, a Gelfoam ${ }^{\circledR}$ plate can be used to cover the skull opening. Muscles and skin are sutured. Finally the skin is covered with sterile dressing.

Postoperative care: antibiotic for 24 hours, as well as monitoring for CSF leaks, hemorrhage or edema of the brainstem and cerebellum. Oral steroids are prescribed for one week. Analgesics, together with antineuritic agents are gradually withdrawn over a period of 7 to 15 days.

\section{Follow-up}

Patients were assessed every four months during the first postoperative year and then annually. Neuropathic pain control effectiveness was evaluated based on a scale created by our team and successfully applied to all our patients. In this scale, four levels of response were considered, which were designated by letters (A-D) in ascending order (Table 1). At each postoperative evaluation, patients were questioned about the presence of pain crisis, its severity, response to drug treatment and impact on their quality of life. Total absence of neuralgic episodes, during the period between surgery and each evaluation time point was classified as category "A". Conversely, surgical treatment total failure with pain episodes of frequency or intensity similar to those prior to surgery was considered "D" category. The intermediate stages between these categories were assessed as described in Table 1. Complications were also recorded.

\section{Results}

\section{Demographics and TN characteristics}

Twenty-six patients were included in the study (17 women, 9 men). Mean age was 60.3 years (range: 34-82 years). TN cases associated with vascular compression were 19 (73.1\%), two cases $(7.7 \%)$ were associated with neurocysticercosis-related arachnoiditis. The remaining cases $(n=4,15.3 \%)$ were associated with traumatic brain injury, subarachnoid hemorrhage due to aneurysm, multiple sclerosis and post-herpetic neuralgia (one case each). Most patients $(n=20,77 \%)$ had received prior pharmacological 
treatment for 24-36 months. The rest ( $n=6,23.1 \%)$, had a history of medical treatment of more than 36 months. Carbamazepine was the most commonly used drug ( $n=14 ; 53.9 \%)$, followed by oxcarbazepine $(n=5,19.2 \%)$. None of the patients had MRI-identified structural lesions. Pain was reported more frequently on the right side ( $n=17,65.5 \%)$. The most common pain localization was simultaneous involvement of V2 and V3 branches ( $n=14,53.9 \%$ ) (Table 2).

\section{Intraoperative findings}

The artery that most commonly produced trigeminal nerve compression was SCA ( $n=11,42.3 \%)$, followed by AICA and arachnoiditis ( $n=5,19.2 \%$, respectively). In three cases (11.5\%), only venous compression was documented (Table 2, Fig. 2). In two patients there was no vascular compression or any other finding explaining the neuralgia; these cases had a history of multiple sclerosis and herpes zoster virus infection, respectively. In all cases, the nerve was dissected and insulating material was placed. In 12 patients (46.1\%), the surgical procedure was assisted by endoscopy.

\section{Follow-up and therapeutic results assessment}

Pain was significantly reduced in all patients during the immediate postoperative period. Based on the proposed scale (Table 1), four months after surgery, and with subsequent reevaluations for at least 36 months, absolute cure was found to be achieved in 18 patients $(69.2 \%$, class A). Seven patients $(27 \%)$ had acceptable pain control $(7.27 \%$, class B). Only one case reported persistence of painful episodes and, although the pain decreased in frequency and intensity, it required the same pre-surgical drug treatment (class C) (Table 3).

\section{Postoperative Complications}

Sixteen patients $(62 \%)$ evolved without early or late complications. Immediate postoperative complications included two cases of hearing loss $(7.7 \%)$, one of which was resolved within the first 12 months, and the other had permanent loss. Another patient developed a surgical wound infection, with a permanent facial paralysis complication (House-Brackmann III). One patient experienced delimited brainstem ischemia, which caused a ventral pontine syndrome with cross paralysis (MillardGubler syndrome). These cases demonstrated a
Table 2. Clinical characteristics and surgical findings

\begin{tabular}{l|c|}
\hline Characteristic & $\mathbf{n}(\%)$ \\
\hline Period under pre-surgical drug treatment & \\
2-3 years & $20(77 \%)$ \\
$3-5$ years & $3(11.5 \%)$ \\
$>5$ years & $3(11.5 \%)$ \\
\hline Neuralgia laterality & \\
Right & $17(65.5 \%)$ \\
Left & $8(30.7 \%)$ \\
Bilateral & $1(3.8 \%)$ \\
Painful dermatomes & \\
V1 & $3(11.5 \%)$ \\
V2 & $6(23.1 \%)$ \\
V1 + V2 & $1(3.8 \%)$ \\
V2 + V3 & $14(53.9 \%)$ \\
V1 + V2 + V3 & $2(7.7 \%)$ \\
Surgical findings & \\
SCA compression & $11(42.3 \%)$ \\
AlCA compression & $5(19.2 \%)$ \\
Venous complex compression & $2(7.7 \%)$ \\
Superior petrosal vein compression & $1(3.8 \%)$ \\
Arachnoiditis & $5(19.3 \%)$ \\
None & $2(7.7 \%)$ \\
AlCA: anterior-inferior cerebellar artery; SCA: superior cerebellar artery.
\end{tabular}

significant recovery with rehabilitation one year after surgery. There was also a case of each of the following (all treated and with early resolution without permanent complications): supratentorial subarachnoid hemorrhage, facial paralysis (House-Brackmann II), nystagmus, cerebellar syndrome, headache and CSF fistula. In the long term, 22 patients evolved without permanent complications $(84.6 \%)$. No deaths associated with the procedure were recorded (Table 3 ).

\section{Discussion}

With the advent of the surgical microscope, Janetta was able to successfully implement MVD surgery, which so farhas been the most popular method and has produced the best results for the treatment of $\mathrm{TN}^{6,18,19}$. Since then, improving the surgical technique has been sought in order to minimize harm derived from the approach and thus prevent complications. That is why a large number of variants of MVD surgery have been described for the treatment of TN, but none is perfect ${ }^{9-15}$. In this manuscript, we present our experience with 26 cases undergoing trigeminal vascular decompression surgery using a minimally-invasive asterional approach.

\section{Surgical technique}

Surgical results largely depend on the placement of the patient in an adequate position (Fig. $1 \mathrm{~B}$ and C). 
Table 3. Surgical treatment effectiveness at $\mathbf{3 6}$ months. Surgical findings and clinical evolution

\begin{tabular}{|c|c|c|c|c|c|c|}
\hline & \multirow[t]{2}{*}{$n(\%)$} & Gender, n (\%) & \multirow[t]{2}{*}{ Age (years) } & \multirow[t]{2}{*}{ Surgical findings } & \multirow[t]{2}{*}{ Temporary complications } & \multirow[t]{2}{*}{ Permanent complications } \\
\hline & & $\begin{array}{l}\text { Males } \\
\text { Females }\end{array}$ & & & & \\
\hline A & $18(69.2 \%)$ & $\begin{array}{l}12(46.1 \%) \\
6(23.1 \%)\end{array}$ & $60.4(34-82)$ & $\begin{array}{l}\text { Artery } 11(42.3 \%) \\
\text { Vein } 3(11.5 \%) \\
\text { Arachnoiditis } 3(11.5 \%) \\
\text { None } 1(3.8 \%)\end{array}$ & $\begin{array}{l}\text { Headache } 1(3.8 \%) \\
\text { CSF fistula } 1(3.8 \%) \\
\text { Hearing loss } 2(7.7 \%) \\
\text { SAH } 1(3.8 \%) \\
\text { Facial paralysis } 1(3.8 \%) \\
\text { Cerebellar syndrome } 1(3.8 \%)\end{array}$ & $\begin{array}{l}\text { Hearing loss } 1(3.8 \%) \\
\text { Tinnitus } 1(3.8 \%)\end{array}$ \\
\hline B & $7(27 \%)$ & $\begin{array}{l}5(19.2 \%) \\
2(7.7 \%)\end{array}$ & $60.3(46-76)$ & $\begin{array}{l}\text { Artery } 4(15.4 \%) \\
\text { Vein } 0(0 \%) \\
\text { Arachnoiditis } 2(7.7 \%) \\
\text { None } 1(3.8 \%)\end{array}$ & $\begin{array}{l}\text { Wound infection } 1(3.8 \%) \\
\text { Cerebral ischemia } 1(3.8 \%)\end{array}$ & $\begin{array}{l}\text { Facial paralysis } 1(3.8 \%) \\
\text { Millard-Gubler sx. } 1 \text { (3.8\%) }\end{array}$ \\
\hline C & $1(3.8 \%)$ & $\begin{array}{c}0(0 \%) \\
1(3.8 \%)\end{array}$ & 60 & Artery $1(3.8 \%)$ & Nystagmus 1 (3.8\%) & - \\
\hline D & $0(0 \%)$ & - & & - & - & - \\
\hline
\end{tabular}

The lateral position allows optimal visibility of the surgical area in the rostral-caudal direction, facilitates exposure of the trigeminal neurovascular complex without affecting venous return and prevents overstretching of the neck, which reduces the frequency of postoperative pain ${ }^{9,12,15,19}$. Regarding the skin incision, localization of the occipital and atrial nerves should be considered in order to avoid injury and, thereby, local postoperative pain ${ }^{9}$. When dissecting soft tissues, we agree with Tomasello, et al. (2016), who emphasize avoiding the use of monopolar electrocautery, since it significantly damages blood vessels, nerves and muscles ${ }^{9}$. This damage causes atrophy, fibrosis and subsequent retraction, which contributes to permanent morbidity of the patient. In our series, no patient reported significant complications due to skin or muscle damage.

The asterional approach allows practicing small craniotomies, so that we have been able to optimally work with a bone window average diameter of $21 \mathrm{~mm}$ (range: $18-25 \mathrm{~mm}$ ). This field allows adequate visualization, which avoids the need for wide tissue removal. It is essential to avoid accessing the mastoid cells, since their opening increases the risk of CSF fistula and serious infectious processes ${ }^{9,15,19}$. Once the cerebellum is exposed, the use of retractors should be avoided, which can promote contusions, hematomas or cerebellar edema. However, when necessary, neurosurgeons should not hesitate to gently use them to contain the cerebellar lobe ipsilateral to the approach, since this maneuver facilitates visualization of the nerve $\mathrm{e}^{10,13,15,18-20}$.
The delicate and complete dissection of the nervous segment and adjacent vessels constitutes a fundamental step of the procedure. It allows identification of vascular compression or its absence ${ }^{10}$. At this point it is decided whether or not endoscope-assisted neurosurgery will be performed. Neuroendoscopy is a useful tool that compensates for surgical microscope limitations ${ }^{21}$. Some neurosurgeons have proposed the use of this tool in all MVD surgical procedures $22-24$. However, based on our experience and that of other authors ${ }^{9}$, we consider neuroendoscopy should be restricted to cases where the neural pathway is difficult to visualize, or when the area of compression is located at a point of difficult access ${ }^{21}$. Its routine use, in the hands of an unskilled surgeon, might even jeopardize patient integrity and increase the frequency of complications associated with its use, such as hemorrhages and lesions of the cerebellar nerve or adjacent cranial nerve ${ }^{19,24,25}$.

\section{Surgical findings}

Arterial nerve compression was, as in other series, the main cause of neuralgia in our patients $(61.6 \%)^{4,11,12,18,23,26}$. According to the literature, venous compression ranges from 6 to $38 \%$ as a cause of $\mathrm{TN}^{11,14,23,26}$. In our series, three patients (12\%) had venous compression, and the placement of insulating material satisfactorily resolved pain episodes, unlike observations reported by other authors, where MVD was not always effective in cases of venous compression ${ }^{12,27}$. 


\section{Therapeutic result}

One of the most critical aspects in the assessment of any treatment, regardless of its nature, is the possibility of evaluating whether it works ${ }^{28}$. Our work team developed a scale for qualitative measurement of the perception of the patient's neuralgic crisis from the surgical intervention until the moment of each assessment, as well as patient response to pharmacological treatment, whenever necessary. This scale was applied every four months after surgery during the first year of treatment, and subsequently every year. We consider that its application is simple, brief and accessible, and can even be carried out through a nonface-to-face interview with the patient. Considering the percentage of cases without pain after 36 months (class $A, 69 \%$ ), our results are within the range of success reported in most series. If these cases are added those cases where pain persisted but was relieved with non-steroidal analgesics $(27 \%)$, our acceptable pain control rate reaches $96 \%$, which even exceeds that of other reports $8,11,15,18-20$. None of our patients required re-intervention due to inadequate pain control. Epidemiological characteristics and surgical findings between successfully treated groups and those that were not are similar, and thus probably there are factors other than those herein studied that may influence on pain total eradication. However, the limited number of patients makes it difficult to obtain more accurate conclusions.

\section{Postsurgical complications}

When surgical techniques are described, not all authors report the complications experienced by their patients ${ }^{9,10}$. We believe that reporting these events is valuable, since it allows other surgeons, especially those who are on training stages, to have a direct insight on that which they might face in daily practice. Although most complications are associated with the execution of the technique and therefore with the surgeon's ability, avoiding some of these events is sometimes inevitable.

The most commonly reported complications after a MVD procedure are: cerebellar compression damage, CSF fistula (due to non-hermetic closure of the dura mater or damage to the mastoid cells) and hearing loss due to a lesion in the cochlear branch of the VIII cranial nerve ${ }^{13,26}$. The frequency of each one of these complications varies from one series to another. Broggi et al. (2000) reported a prevalence of hearing loss of $6.8 \%$ in a series of $250 \mathrm{TN}$ cases treated with $M V D^{11}$. The prevalence in our series was slightly higher. However, in Broggi's work, intraoperative auditory evoked potentials monitoring was performed, which allowed alerting the surgeon when cranial nerve VIII was accidentally manipulated or tensioned. In our setting it is not plausible having this technology available in all procedures, since most of them are carried out at public hospitals with limited resources. Other authors report hearing loss rates of 1.5-19\% ${ }^{12,15,20,29}$.

The incidence of CSF fistula ranges from 2.5 to $15 \%^{11,12,15,18,20}$. Our patients were within this range, with an incidence of $4 \%$. Facial paralysis is found at an average of $0.6-7.6 \%$ of cases $^{18,20,29}$, and it is generally a temporary condition. Two patients (8\%) of our series were detected with cranial nerve VII deficit, one of them transient (House-Brackmann II) and the other with partial remission (House-Brackmann III, associated with surgical wound infection). There were no cases of meningitis, cerebral infarction, hematomas, hydrocephalus, extraocular muscle paralysis or mortality associated with the surgical procedure.

\section{Conclusions}

Trigeminal MVD surgery by means of an approach through the asterional point is an alternative with similar results to the classical retrosigmoid approach to treat TN, but which adds the benefits of minimallyinvasive surgery principles. Inter-institutional efforts are necessary in order to conduct prospective studies with a larger number of patients and long-term followup, with standardized assessment tools.

\section{Conflict of interests}

The authors declare that they have no conflicts of interest.

\section{References}

1. Patel SK, Liu JK. Overview and history of trigeminal neuralgia. Neurosurg Clin N Am. 2016;27(3):265-76.

2. Eller JL, Raslan AM, Burchiel KJ. Trigeminal neuralgia: definition and classification. Neurosurg Focus. 2005;18(5):E3.

3. van Hecke O, Austin SK, Khan RA, Smith BH, Torrance N. Neuropathic pain in the general population: A systematic review of epidemiological studies: Pain. 2014;155(4):654-62.

4. Chen G, Wang X, Wang L, Zheng J. Arterial compression of nerve is the primary cause of trigeminal neuralgia. Neurol Sci. 2014;35(1):61-6.

5. Hodaie M, Coello AF. Advances in the management of trigeminal neuralgia. J Neurosurg Sci. 2013;57(1):13-21.

6. Al-Quliti KW. Update on neuropathic pain treatment for trigeminal neuralgia. The pharmacological and surgical options. Neurosci Riyadh Saudi Arab. 2015;20(2):107-14.

7. Cole CD, Liu JK, Apfelbaum RI. Historical perspectives on the diagnosis and treatment of trigeminal neuralgia. Neurosurg Focus. 2005;18(5):E4. 
8. Jannetta PJ. Arterial compression of the trigeminal nerve at the pons in patients with trigeminal neuralgia. J Neurosurg. 2007;107(1):216-37.

9. Tomasello F, Esposito F, Abbritti RV, Angileri FF, Conti A, Cardali SM et al. Microvascular decompression for trigeminal neuralgia: Technical refinement for complication avoidance. World Neurosurg. 2016: 94:26-31.

10. da Silva O, de Almeida C, Iglesio R, de Navarro J, Teixeira M, Duarte K. Surgical variation of microvascular decompression for trigeminal neuralgia: A technical note and anatomical study. Surg Neurol Int. 2016; 7(22):571.

11. Broggi G, Ferroli P, Franzini A, Servello D, Dones I. Microvascular decompression for trigeminal neuralgia: comments on a series of $250 \mathrm{ca}-$ ses, including 10 patients with multiple sclerosis. J Neurol Neurosurg Psychiatry. 2000;68(1):59-64.

12. Campero A, Campero A, Ajler P. Descompresión microvascular en neuralgia del trigémino: Reporte de 36 casos y revisión de la literatura. Surg Neurol Int. 2014;5(12):441.

13. McLaughlin MR, Jannetta PJ, Clyde BL, Subach BR, Comey CH, Resnick DK. Microvascular decompression of cranial nerves: lessons learned after 4400 operations. J Neurosurg. 1999;90(1):1-8.

14. Kabatas S, Karasu A, Civelek E, Sabanci AP, Hepgul KT, Teng YD. Microvascular decompression as a surgical management for trigeminal neuralgia: long-term follow-up and review of the literature. Neurosurg Rev. 2009;32(1):87-93; discussion 93-94.

15. Forbes J, Cooper C, Jermakowicz W, Neimat J, Konrad P. Microvascular decompression: Salient surgical principles and technical nuances. $J$ Vis Exp. 2011;(53):e2590.

16. Day JD, Jordi XK, Manfred T, Takanori F. Surface and superficial surgical anatomy of the posterolateral cranial base: Significance for surgical planning and approach. neurosurgery. 1996;38(6):1079-84 .

17. Ucerler H, Govsa F. Asterion as a surgical landmark for lateral cranial base approaches. J Cranio-Maxillofac Surg. 2006;34(7):415-20.
18. Chakravarthi PS, Ghanta R, Kattimani V. Microvascular decompression treatment for trigeminal neuralgia: J Craniofac Surg. 2011;22(3):894-8.

19. Toda H, Goto M, Iwasaki K. Patterns and variations in microvascular decompression for trigeminal neuralgia. Neurol Med Chir (Tokyo). 2015; 55(5):432-41.

20. Venkataramana N, Bansal A, Jagannath P, Ravichandra M. Outcome of microvascular decompression for trigeminal neuralgia using autologous muscle graft: A five-year prospective study. Asian J Neurosurg. 2012; 7(3):125.

21. Chen MJ, Zhang WJ, Yang C, Wu YQ, Zhang ZY, Wang Y. Endoscopic neurovascular perspective in microvascular decompression of trigeminal neuralgia. J Cranio-Maxillofac Surg. 2008;36(8):456-61.

22. Piazza M, Lee JYK. Endoscopic and microscopic microvascular decompression. Neurosurg Clin N Am. 2016;27(3):305-13.

23. Halpern CH, Lang S-S, Lee JYK. Fully endoscopic microvascular decompression: Our early experience. Minim Invasive Surg. 2013:2013:1-5.

24. Bohman LE, Pierce J, Stephen JH, Sandhu S, Lee JYK. Fully endoscopic microvascular decompression for trigeminal neuralgia: technique review and early outcomes. Neurosurg Focus. 2014;37(4):E18.

25. Marcus HJ, Cundy TP, Hughes-Hallett A, Yang G-Z, Darzi A, Nandi D. Endoscopic and keyhole endoscope-assisted neurosurgical approaches: A qualitative survey on technical challenges and technological solutions. Br J Neurosurg. 2014:28(5):606-10.

26. Teixeira MJ, Siqueira SRDT, Almeida GM. Percutaneous radiofrequency rhizotomy and neurovascular decompression of the trigeminal nerve for the treatment of facial pain. Arq Neuropsiquiatr. 2006;64(4):983-9.

27. Hong W, Zheng X, Wu Z, Li X, Wang X, Li Y, et al. Clinical features and surgical treatment of trigeminal neuralgia caused solely by venous compression. Acta Neurochir (Wien). 2011;153(5):1037-42.

28. Lee JYK. Measurement of trigeminal neuralgia pain. Neurosurg Clin $N$ Am. 2016;27(3):327-36.

29. Oesman C, Mooij JJA. Long-term follow-up of microvascular decompression for trigeminal neuralgia. Skull Base. 2011;21(5):313-22. 